\title{
Sodium sulfate heptahydrate: direct observation of crystallization in a porous material
}

\author{
Andrea Hamilton ${ }^{1,3}$, Christopher Hall ${ }^{1}$ and Leo Pel ${ }^{2}$ \\ ${ }^{1}$ School of Engineering and Electronics and Centre for Materials Science and Engineering, \\ The University of Edinburgh, The King's Buildings, Edinburgh EH9 3JL, UK \\ ${ }^{2}$ Department of Applied Physics, Eindhoven University of Technology, PO Box 513, 5600 MB \\ Eindhoven, The Netherlands \\ E-mail: andrea.hamilton@ed.ac.uk
}

Received 16 June 2008, in final form 22 August 2008

Published 15 October 2008

Online at stacks.iop.org/JPhysD/41/212002

\begin{abstract}
It is well known that sodium sulfate causes salt crystallization damage in building materials and rocks. However since the early 1900s the existence of the metastable heptahydrate has been largely forgotten and almost entirely overlooked in scientific publications on salt damage mechanics and on terrestrial and planetary geochemistry. We use hard synchrotron x-rays to detect the formation of this metastable heptahydrate on cooling a porous calcium silicate material saturated with sodium sulfate solution. The heptahydrate persists indefinitely and transforms to mirabilite only below $0{ }^{\circ} \mathrm{C}$. At the transformation, which is rapid, the solution is highly supersaturated with respect to mirabilite. We estimate that crystallization of the heptahydrate and of mirabilite have associated Correns pressures of about 9 and $19 \mathrm{MPa}$, respectively, exceeding the tensile strength of building stones. We detect lattice strains in the salts from x-ray measurements consistent with these values.
\end{abstract}

(Some figures in this article are in colour only in the electronic version)

\section{Introduction}

Hydrated sodium sulfate causes salt crystallization damage in building materials and rocks [1], and is found in Antarctic ice [2], and in salt lakes [3]. Landform alteration is the result of salt weathering on Earth and probably on Mars [4]. The well-known sodium sulfate decahydrate $\mathrm{Na}_{2} \mathrm{SO}_{4} \cdot 10 \mathrm{H}_{2} \mathrm{O}$, mirabilite, is thought to form in the icy brines on the moons of Jupiter [5,6]. In stone decay in buildings and archaeological sites, sodium sulfate is regarded as particularly damaging, probably because this salt can easily form a solution which is highly supersaturated with respect to mirabilite [7]. Correns showed that a salt in contact with its supersaturated solution can produce a crystallization pressure $[8,9]$ in a host matrix [10]. However many questions remain about the

\footnotetext{
3 Author to whom any correspondence should be addressed.
}

destructive nature of sodium sulfate [11], not least because of the absence of direct evidence that mirabilite forms in building stones and porous rocks. Now, using hard synchrotron $\mathrm{x}$-rays to obtain in situ powder diffraction patterns [12] we observe directly a salt crystallization sequence within a porous matrix on cooling. We have used quantitative ${ }^{23} \mathrm{Na}$ NMR independently to monitor the salt concentration in the solution [13]. Cooling aqueous sodium sulfate solutions in a high porosity calcium silicate material $[14,15]$, we find that the salt first formed on cooling is not mirabilite but the metastable hydrate $\mathrm{Na}_{2} \mathrm{SO}_{4} \cdot 7 \mathrm{H}_{2} \mathrm{O}$ [16], a crystal of which is shown in figure 1. Although it is invariably assumed that mirabilite is the salt formed in salt damage processes, the early scientific literature contains several extensive studies of the metastable heptahydrate $[16,17]$. These show that the heptahydrate is almost always the first hydrate to crystallize from supersaturated sodium sulfate solutions on cooling, and 

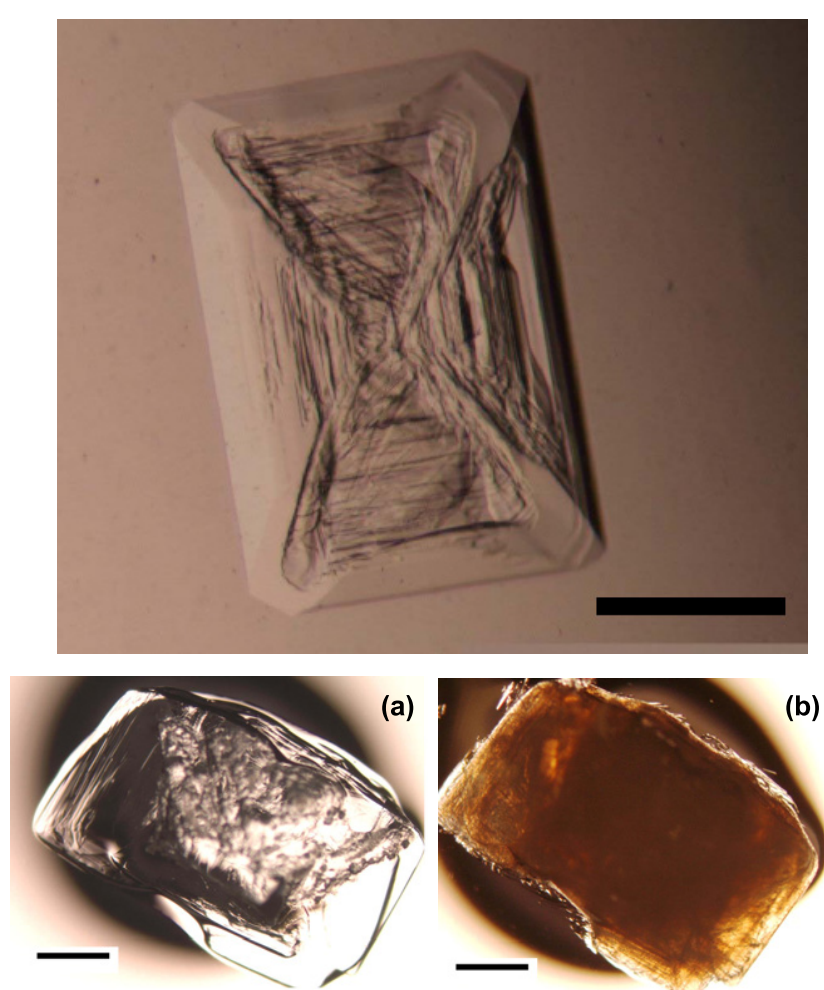

Figure 1. (Top) A crystal of sodium sulfate heptahydrate grown by cooling a $3.4 \mathrm{~m} \mathrm{Na}_{2} \mathrm{SO}_{4}$ aqueous solution on an ice bath. Scale bar $600 \mu \mathrm{m}$. (Bottom) A heptahydrate crystal in mineral oil (a) before and $(b)$ after pseudomorphic transformation to mirabilite caused by momentary contact with a seed crystal. The transformed crystal is strongly opaque and noticeably textured. Scale bars $1 \mathrm{~mm}$.

that mirabilite forms only with difficulty. The nineteenth and early twentieth century scientific literature contrasts sharply with the more recent literature in emphasizing the prominence of the heptahydrate.

\section{Experiments}

All experiments were carried out on cylindrical plugs of hydrated calcium silicate $22 \mathrm{~mm}$ diameter $\times 45 \mathrm{~mm}$ long, a construction material chosen for its high porosity (volume fraction porosity of 0.90 and mean pore radius $0.33 \mu \mathrm{m}$ ) and composed mainly of elongated particles of xonotlite [14, 15]. The cores were capillary saturated with 3.4 molal (m) sodium sulfate solution and either encased in a PE sleeve ( $\mathrm{x}-$ ray measurements) or wrapped in hydrophobic PTFE tape (NMR measurements) to prevent evaporation. The $3.4 \mathrm{~m}$ concentration used is close to the solubility of thenardite at 30$40^{\circ} \mathrm{C}$, and typical of the more concentrated solutions formed by taking up water into stones which have previously deposited thenardite by evaporation.

X-ray data were obtained on beamline 16.4 at the UK Synchrotron Radiation Source, Daresbury. Plug and sleeve were mounted vertically in a thermostatted cooling block, and rotated about the cylinder axis. The sample temperature was estimated from the measured temperature of the cooling block by applying Newton's law of cooling. A collimated beam of polychromatic x-rays passed through the sample and Bragg scattered $\mathrm{x}$-rays were intercepted at fixed scattering angles by a bank of three energy-dispersive Ge detectors [18]. The sample holder was cooled from 48 to $-15^{\circ} \mathrm{C}$ over $172 \mathrm{~min}$. The powder diffraction reference pattern of the heptahydrate was obtained in a separate series of experiments using the same synchrotron instrumentation [12]. Replicate calcium silicate plugs cooled at an overall cooling rate of $30^{\circ} \mathrm{Ch}^{-1}$ were examined with time-resolved ${ }^{23} \mathrm{Na} \mathrm{NMR}$ measurements of solution concentration using the method described by Rijniers et al [13].

\section{Results}

The in situ X-ray measurements we report provide the first direct evidence that heptahydrate nucleates in preference to mirabilite when a capillary saturated porous material is cooled. During cooling, the dissolved salt concentration in the porous material remains constant at first while the solution becomes increasingly supersaturated with respect to both mirabilite and heptahydrate as their solubilities fall. The $\mathrm{X}$-ray sample temperature was estimated from ${ }^{23} \mathrm{Na} \mathrm{NMR}$ experiments which showed (indirectly) that heptahydrate crystallizes reproducibly at $10^{\circ} \mathrm{C}$ in saturated calcium silicate cores when cooled at a rate of around $30^{\circ} \mathrm{Ch}^{-1}$. We calculate the cooling rate of the samples in the $\mathrm{x}$-ray experiments by applying Newton's cooling law to the measured cooling rate of the temperature-controlled sample block, knowing the initial sample temperature and assuming that heptahydrate precipitation occurs at $10^{\circ} \mathrm{C}$. From this analysis we calculate an overall sample cooling rate of around $22^{\circ} \mathrm{Ch}^{-1}$ from the start of the experiment to heptahydrate precipitation, close to the NMR sample cooling rate of $30^{\circ} \mathrm{Ch}^{-1}$. NMR experiments suggest that the cooling rate would have to be decreased by at least an order of magnitude for the temperature of precipitation to rise by a few degrees centigrade. At a temperature which we estimate to be $10^{\circ} \mathrm{C}$ we observe a spontaneous and sudden crystallization of sodium sulfate heptahydrate as shown by the changes in the XRD pattern (figure 2 (Left)). NMR data show that there is a sharp fall in sodium sulfate concentration in solution (figure 3 ) to a value close to the heptahydrate solubility $(2.10 \mathrm{~m})$. It is evident from figure 3 that on cooling the solution concentration is slightly higher than the equilibrium curve. The rate of crystallization depends on the cooling rate which is too rapid for equilibrium to be reached fully in the short time the system remains at each temperature. The equilibrium curve may be more closely followed with a slower cooling rate. At around $-2{ }^{\circ} \mathrm{C}$, based on the calculated sample cooling rate, there is a dramatic change in the XRD pattern and a further fall in solution concentration as the heptahydrate transforms to mirabilite. This is in good agreement with the measured ${ }^{23} \mathrm{Na}$ NMR conversion temperature of around $-4{ }^{\circ} \mathrm{C}$. The $\mathrm{x}$-ray sample is cooled to an estimated final temperature of $-6{ }^{\circ} \mathrm{C}$ and we do not detect the formation of ice. We find in general that heptahydrate shows a greater tendency to convert to mirabilite at temperatures around or below $0{ }^{\circ} \mathrm{C}$.

Using the 103 reflection of heptahydrate and the 002 reflection of mirabilite, we can follow the transformation kinetics (figure 2 (Right)). The nucleation and initial rapid crystal growth of the heptahydrate occur over about $7 \mathrm{~min}$; 

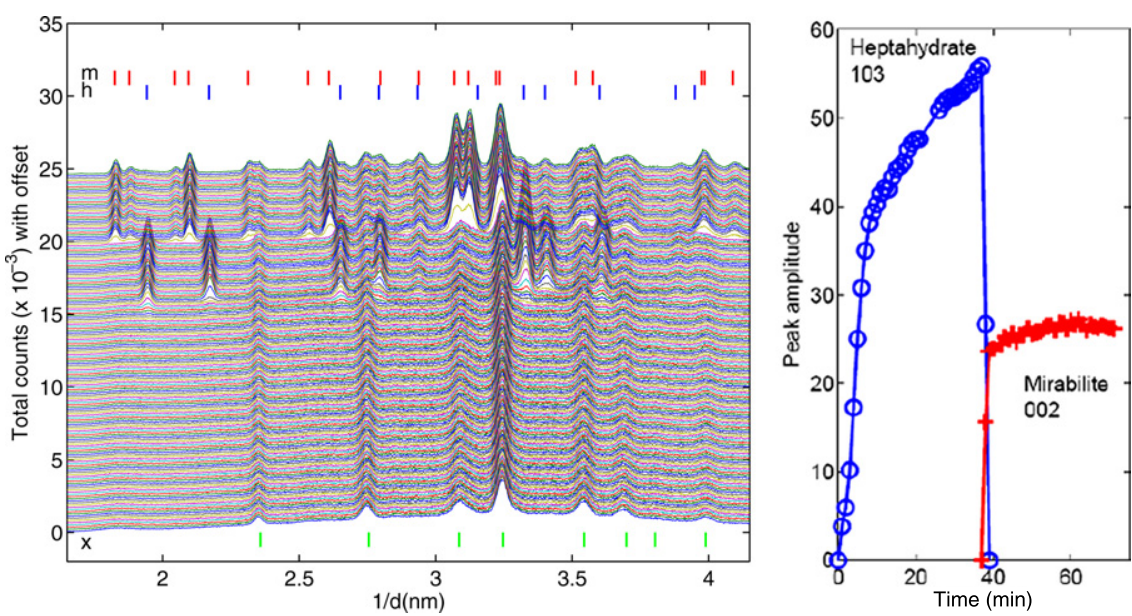

Figure 2. (Left) Energy-dispersive x-ray diffraction patterns obtained during cooling of a cylindrical calcium silicate core saturated with a $3.4 \mathrm{~m}$ sodium sulfate solution. Patterns were recorded every $30 \mathrm{~s}$ from a starting sample temperature of $48^{\circ} \mathrm{C}$ and show precipitation of heptahydrate at $10^{\circ} \mathrm{C}$ and mirabilite at $-2^{\circ} \mathrm{C}$. Markers show expected positions of the main diffraction peaks of xonotlite $(\mathbf{x})$, the main mineral phase of the calcium silicate core (JCPDS card 23-125); of heptahydrate (h) [12]; and of mirabilite (m) (JCPDS card 75-1077). (Right) Growth of the heptahydrate 103 reflection $(O)$ and of the mirabilite $002(+)$ reflection from synchrotron x-ray diffraction data.

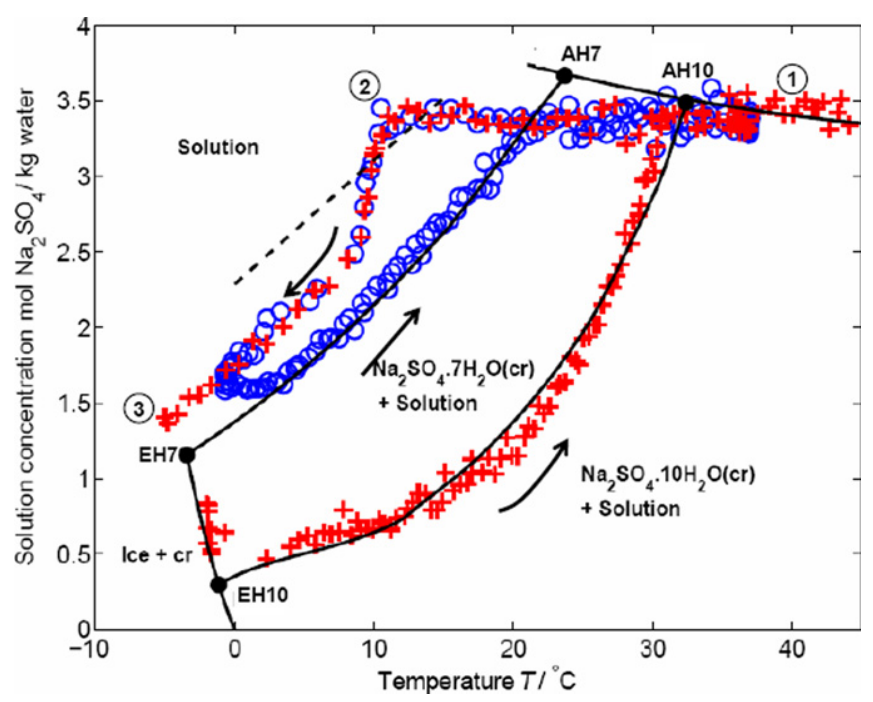

Figure 3. Dissolved salt concentrations obtained by ${ }^{23} \mathrm{Na}$ NMR measurements on calcium silicate cores saturated with $3.4 \mathrm{~m}$ aqueous sodium sulfate solution. Experimental data from two cooling/heating runs are superimposed on the $\mathrm{Na}_{2} \mathrm{SO}_{4}-\mathrm{H}_{2} \mathrm{O}$ phase diagram defined by solubility curves (solid lines) for mirabilite, heptahydrate, thenardite and ice. The dotted line shows the supersolubility curve for heptahydrate [16], an approximate upper bound on the supersaturation which can be maintained before crystallization occurs. EH10 and EH7 are the eutectic points for heptahydrate-ice and mirabilite-ice; AH7 is the co-existence point for heptahydrate-thenardite; and AH10 that for mirabilite-thenardite. (1) marks the start of a cooling experiment, (2) the crystallization of heptahydrate and (3) the crystallization of mirabilite. Points $\bigcirc$ : data obtained on cooling at $30^{\circ} \mathrm{Ch}^{-1}$ from $40^{\circ} \mathrm{C}$ to a minimum temperature of $0{ }^{\circ} \mathrm{C}$ showing heptahydrate crystallization occurring at about $10^{\circ} \mathrm{C}$; on reheating, the solution concentration follows the heptahydrate solubility curve. Points +: data on cooling at $30^{\circ} \mathrm{Ch}^{-1}$ to a minimum temperature of $-4{ }^{\circ} \mathrm{C}$, where heptahydrate transforms to mirabilite and the solution concentration decreases to lie on the mirabilite solubility curve. On reheating, the solution follows the mirabilite solubility curve. thereafter there is a slow increase in the intensity of the 103 and other diffraction peaks as cooling continues. The $30 \%$ increase in mass of crystals corresponds to the decrease in solubility of heptahydrate with temperature. After the initial crystallization heptahydrate crystals occupy $28 \%$ of the pore space; this increases to $41 \%$ as the sample cools to about $-2{ }^{\circ} \mathrm{C}$. The transformation of heptahydrate to mirabilite is spectacularly fast, and is complete in less than $2 \mathrm{~min}$. In the fully transformed system at $-2{ }^{\circ} \mathrm{C}$, we calculate from solubility data [19] that $64 \%$ of the pore volume is occupied by solid mirabilite in equilibrium with saturated sodium sulfate solution $\left(0.27 \mathrm{~m} \mathrm{Na}_{2} \mathrm{SO}_{4}\right)$. Once nucleated, crystal growth of mirabilite is evidently rapid. As mirabilite is considerably less soluble than the heptahydrate, strong concentration gradients drive ion diffusion through solution towards the growing mirabilite crystals. Mirabilite and heptahydrate have different crystal structures, but mirabilite crystals grow in close proximity to pre-existing heptahydrate in a system which contains little solution. Under the microscope, we see a rapid pseudomorphic replacement of heptahydrate by mirabilite, and something similar undoubtedly occurs in the confined pore space which also contains rather little solution.

Careful analysis of $\mathrm{x}$-ray diffraction peak shifts provides direct evidence of lattice strain in the salt hydrate crystals as they grow and are confined by the matrix on which they exert increasing stress. Lattice strain estimates were obtained by Gaussian fitting to selected diffraction peaks. This provides accurate values of changes in $d$-spacing, and hence strain, within sequences of diffraction patterns obtained during a single cooling run. Observed strains were corrected for the effects of thermal contraction. In figure 4 we show the compressive deformation of the hydrate lattice during the crystallization process of figure 2 . The $d$-spacing shifts of selected peaks show that (after correcting for thermal contraction) the heptahydrate develops only a small linear compressive strain of not more than about $1 \times 10^{-4}$ during crystallization, but the mirabilite shows a larger compressive 


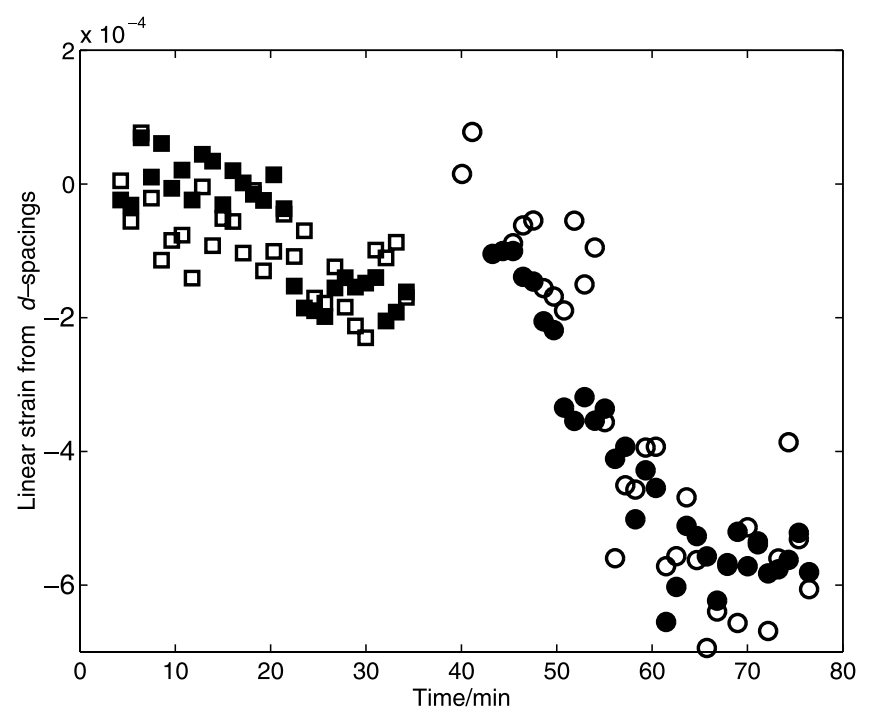

Figure 4. Estimated lattice strains calculated from shifts in $d$-spacings in heptahydrate and mirabilite during salt crystallization. - heptahydrate $105, \square$ heptahydrate 204 reflections, mirabilite 002 , $\bigcirc$ mirabilite 223 peaks. Data are corrected for the effects of thermal contraction due to cooling. Zero strain is taken at the beginning of crystallization for each hydrate.

lattice strain of about $5.5 \times 10^{-4}$ (figure 4.) The compressive strain in mirabilite rises rapidly at first and then stabilizes. We assume an approximate bulk modulus of $20 \mathrm{GPa}$ for both hydrates, based on values measured for two other salt hydrates, ikaite and epsomite [20,21]. We then calculate from the observed lattice strains that the compressive stress in the heptahydrate cannot be more than about $2 \mathrm{MPa}$ but in the mirabilite it is about $11 \mathrm{MPa}$. It should be noted that the calcium silicate matrix used here is a rather unusual porous material, which consists of a loose network of acicular crystals rather than a conventional pore system in a solid matrix. What we present is a novel way of extracting some information on the strain experienced by salt crystals inside a porous matrix.

\section{Discussion}

A link between these phenomena and damage mechanics lies in the Correns equation for crystallization pressure [8], recently reworked by Flatt [9], Coussy [22] and Steiger [23]. The Correns pressure $\Delta P$ in the form derived by Steiger is given by equation (1):

$$
\Delta P=\frac{\nu \boldsymbol{R} T}{V_{\mathrm{m}}}\left(\ln \frac{m}{m_{0}}+\ln \frac{\gamma_{ \pm}}{\gamma_{ \pm, 0}}+\frac{\nu_{w}}{v} \ln \frac{a_{\mathrm{w}}}{a_{\mathrm{w}, 0}}\right),
$$

where $\gamma_{ \pm}$is the mean ion activity, $m$ is the concentration of the solution in moles per $\mathrm{kg}$ water and $a_{\mathrm{w}}$ is the activity of water. Subscript zero indicates a value before crystallization takes place. $v_{\mathrm{w}}$ is the number of water molecules combined in the hydrate, $v$ the stoichiometric number for the ions, $V_{\mathrm{m}}$ the molar volume of the salt, $\boldsymbol{R}$ the gas constant and $T$ the absolute temperature. The Correns pressure is the maximum pressure that a salt crystal growing in a supersaturated solution can exert on the pore wall provided this does not exceed the disjoining pressure associated with the salt crystal-pore wall contact. As is evident, high supersaturations are essential for generating large stresses. Our results allow us to establish conclusively the identity of the precipitating phase in a porous material, to quantify the supersaturations and also to carry out complete mass and volume balances. It is assumed that a crystal makes contact with the pore wall though a film of solution so that growth can be maintained [10]. Pitzer water and ion activities have been calculated using Frezchem [24]. Supersaturations from +15 to $-5{ }^{\circ} \mathrm{C}$ were estimated from heptahydrate solubility data [25]. A fixed pre-crystallization solution concentration of $3.41 \mathrm{~m}$ was used, corresponding to our experimental system. The solubility product of heptahydrate in the temperature range $0-25^{\circ} \mathrm{C}$ and $1 \mathrm{~atm}$ pressure calculated from solubility data over the temperature range $0-23.7^{\circ} \mathrm{C}$ is $\ln K_{\mathrm{sp}}=$ $-45.72755+0.2126744 T-2.176074 \times 10^{-4} T^{2}$ with $T$ the absolute temperature [26]. In our case the solution reaches a supersaturation $\mathrm{m} / \mathrm{m}_{0}$ with respect to heptahydrate of 1.6 at $10^{\circ} \mathrm{C}$ with a calculated crystallization pressure of about 8.8 MPa. The Correns pressure increases rapidly as nucleation temperature falls, primarily because the supersaturation with respect to the heptahydrate solid phase increases.

Just before mirabilite forms at about $-2{ }^{\circ} \mathrm{C}$ the supersaturation with respect to mirabilite is 3.9 and the calculated Correns pressure $P$ is $19.2 \mathrm{MPa}$. These Correns pressures, which set upper bounds on the real stress in the salt crystals, are consistent with our estimates of compressive stress from the observed lattice strains which are lower. The effective stress in the matrix is to a first approximation $\phi P$ where $\phi$ is the volume fraction of solid hydrate in bulk material. From this, we estimate that the bulk stress on crystallization of heptahydrate at $10^{\circ} \mathrm{C}$ cannot be greater than about $2.2 \mathrm{MPa}$; and on crystallization of mirabilite at $-2{ }^{\circ} \mathrm{C}$ cannot exceed about $11 \mathrm{MPa}$. Indeed applying $\phi P$ to the compressive stress calculated from the observed lattice strains we estimate that the actual stresses in the matrix are $0.5 \mathrm{MPa}$ and $6.3 \mathrm{MPa}$ for heptahydrate crystallization at $10{ }^{\circ} \mathrm{C}$ and mirabilite at $-2{ }^{\circ} \mathrm{C}$, respectively. These values sit below the upper bound stresses in the matrix as calculated from the Correns pressure. Stress transfer to the matrix is of course complex since there are both equilibrium and non-equilibrium processes at work and the coupling of solubility to stress ensures that stress relaxation must occur. In equilibrium situations crystals present in the matrix are in equilibrium with the surrounding pore solution. Non-equilibrium effects [7,27] are the result of continued crystal growth from a supersaturated solution (generally requiring long range diffusive transport of ions to the growing crystal to sustain) leading to the development of the Correns crystallization pressure. In practice some combination of both may occur. It appears that the strong crystallization pressures developed in materials saturated with sodium sulphate solution are primarily the result of the difficulty of nucleating mirabilite.

\section{Conclusions}

Our results show that heptahydrate is the first sodium sulfate hydrate to form in a calcium silicate porous matrix on cooling and only converts to mirabilite at temperatures 
below about $0^{\circ} \mathrm{C}$. (There is indirect evidence also for heptahydrate formation limestones [28]). We also quantify the supersaturation attainable in a closed system before crystallization. This allows us to calculate with more accuracy the maximum (limiting) Correns pressure, and the amounts of solid salts formed and the volumes and compositions of the solution at every stage. From the analysis of diffraction peak positions we are able to investigate the strain imposed on the crystals by the matrix and compare the corresponding stress with these calculated Correns pressures. We conclude that the sudden burst of mirabilite crystallization at low temperatures and associated strain produced sheds new light on the ability of sodium sulfate to damage porous materials. Finally we note that sodium sulfate heptahydrate may be of much wider significance. Gans [29] in his work on the water vapour pressure-temperature phase diagram finds a region of stability for the otherwise metastable heptahydrate at sub-zero temperatures and low relative humidity values. Extrapolating this phase diagram to the conditions of the surface of Mars suggests that heptahydrate formation on Mars is possible [26]. Given the reluctance of mirabilite to nucleate directly from solution, our results also suggest the possibility that heptahydrate as well as mirabilite may occur in salt playas and lakes on Earth, in Antarctic ice and on Jupiter's icy moons [26].

\section{Acknowledgments}

We thank EPSRC for research funding; David Taylor, SRS, Daresbury Laboratory, UK for synchrotron support; a part of this project was supported by the Dutch Technology Foundation (STW).

\section{References}

[1] Goudie A S and Viles H A 1997 Salt Weathering Hazards (Chichester, UK: Wiley)
[2] Ohno H, Igarashi M and Hondoh T 2006 Geophys. Res. Lett. 33 L08501

[3] Sack L A and Last W M 1994 J. Paleolimnol. 10199

[4] Jagoutz E 2006 Adv. Space Res. 38696

[5] Kargel J S, Kaye J Z, Head J W, Marion G M, Sassen R, Crowley J K, Ballesteros O P, Grant S A and Hogenboom D L 2000 Icarus 148226

[6] Marion G M, Kargel J S, Caitling D C and Jakubowski S D 2005 Geochim. Cosmochim. Acta 69259

[7] Flatt R J 2002 J. Cryst. Growth 242435

[8] Correns C W 1949 Discuss. Faraday Soc. 5267

[9] Flatt R J, Scherer G W and Steiger M 2007 Environ. Geol. 52187

[10] Scherer G W 1999 Cem. Concr. Res. 291347

[11] Rodriguez-Navarro C and Doehne E 1999 Earth Surf. Process. Landf. 24191

[12] Hamilton A and Hall C 2008 J. Anal. At. Spectrom. 23840

[13] Rijniers L A, Huinink H, Pel L and Kopinga K 2005 Phys. Rev. Lett. 94075503

[14] Hamilton A and Hall C 2005 J. Build. Phys. 299

[15] Hamilton A and Hall C 2007 J. Build. Phys. 3169

[16] Hartley H, Jones B M and Hutchison G A 1908 J. Chem. Soc. 93825

[17] Loewel H 1850 Ann. Chim. Phys. 2962

[18] Barnes P et al 1998 Nucl. Instrum. Methods B 134310

[19] Gmelin L 1961 Gmelins Handbuch der Anorganischen Chemie Systeme Nr. 21, Natrium (Verlag Chemie $\mathrm{GmbH})$

[20] Lennie A R 2005 Mineral. Mag. 69325

[21] Fortes A D, Wood I G, Alfredsson M, Vocadlo L and Knight K S 2006 Eur. J. Mineral. 18449

[22] Coussy O 2006 J. Mech. Phys. Solids 541517

[23] Steiger M 2005 J. Cryst. Growth 282455

[24] Marion G M and Kargel J S 2008 Cold Aqueous Planetary Geochemistry with FREZCHEM (Berlin/Heidelberg: Springer)

[25] Eddy R D and Menzies A W C 1940 J. Phys. Chem. 44207

[26] Hall C and Hamilton A 2008 Icarus doi:10.1016/j.icarus.2008.07.001

[27] Scherer G W 2004 Cem. Concr. Res. 341613

[28] Rijniers L A 2005 PhD Thesis Technical University of Eindhoven, Netherlands

[29] Gans W 1978 Z. Phys. Chem. 11139 